\title{
Da representação da herança pelo inventariante
}

Francisco Morato

Sem embargo de ser muito segura a intelligencia que a boa doutrina e a jurisprudencia tem dado ao thema acima enunciado, uma ou outra divergencia tem apparecido de onde em onde na opinião de alguns juristas e pragmaticos; divergencia de todo infundada e a nosso ver oriunda do baralhamento ou falta de travação logica dos principios que regem a materia.

Para os poucos que divergem, a duvida manifesta-se particularmente na venda de immoveis, porque, segundo dizem, não sendo a herança pessoa juridica e não sendo o inventariante representante della, a venda só é possivel no nome dos herdeiros, com a annuencia e comparecimento de todos elles ao acto da escriptura, pessoalmente ou por procurador munido de poderes especiaes. $O$ inventariante não teria qualidade para figurar na venda e nunca lhe seria licito outorgal-a no nome da herança, pela razão de carecer a successão hereditaria de personalidade juridica.

São pontos de vista indefensaveis, contrarios á pureza e rigor das normas, condemnados na pratica quotidiana dos auditorios de justiça, no estylo dos interpretes, na expressão dos julgados e até no uso correntio da linguagem vulgar.

Desdobra-se o thema em tres principaes questões, uma relativa á natureza juridica do cargo de inventariante, outra á comprehensão e latitude de seus poderes, a terceira á 
maneira, modo ou nome com que deve a herança figurar nos actos juridicos.

Quanto ao primeiro topico, está assentado na doutrina e na jurisprudencia que o inventariante não é um simples depositario, a quem compete apenas a guarda e conservação dos bens inventariados, senão tambem um administrador e possuidor da herança commum, a quem tocam as funcções e deveres attinentes á administração e posse em que se acha legalmente investido. Pela investidura e attribuições do cargo, é equiparado a um procurador ou mandatario geral.

Esta é a licção de Coelho da Rocha, reproảuzida nos arts. 2082 - 2086 do codigo civil portuguez, ensinada nos commentarios de Dias Ferreira e Astolpho de Rezende, acolhida pela torrente de nossos praticos e interpretes, consagrada na lettra e espirito de nossa legislação (CoElHo da Rocha: Direito Civil, not. $U$ ao $\S 475$. Dias Ferreira: Cod. Civ. Port. An., vol. IV, pag. 86 - 93. Astolpho de Rezende: Manual do Cod. Civ., vol. XX, n. 84. Clovis Bevilaqua: Commentarios, vol. VI. pag. 246. Cod. Crvil, arts. 1579 e 1755).

Investido dos encargos de depositario, possuidor e administrador dos bens inventariados, o inventariante é representante da herança como depositario, possuidor e administrador.

Envolve duplo equivoco a affirmação que sobre o assumpto fez um douto jurisconsulto, de que o inventariante não é representante do espolio, visto ser simples guarda e administrador e visto não ser a herança pessoa juridica (Revista Geral de Dir., Leg. e Jurisp., V-403). Duplo equivoco, primeiro porque o administrador é necessariamente representante, em actos de administração, daquelle em cujo nome age e administra; depois porque, si o não ser a herança pessoa juridica fosse motivo para dizer-se que o inventariante não é representante della, chegar-se-ia á conclusão esdruxula 
de que o inventariante não é representante de ninguem ou que opera e administra em nome e por conta propria.

Quanto ao segundo, não menos clara e pacifica é a theoria e a pratica do direito.

$\mathrm{Na}$ dupla qualidade de possuidor e administrador da massa commum, pela propria auctoridade e attributos do cargo, cabe ao inventariante dar andamento aos termos do inventario; ter em boa guarda e cuidados os haveres da herança; attender ás despezas necessarias e uteis de conservação, reparos, cultura e custeamento; cobrar e receber as dividas activas, usando para isso das acções adequadas, receber e vender os fructos e bens que forem de alienar, arrendar as cousas a isso destinadas; usar dos interdictos possessorios, não apenas contra extranhos senão ainda contra os proprios herdeiros, que lhe ameacem, perturbem ou esbulhem a posse.

Competem-lhe em geral todos os poderes de administrador; não assim os de alienar, hypothecar, transigir ou praticar actos que exorbitem da administração ordinaria ou impliquem disposição.

Nos actos de administração ordinaria, age por sí; nos de disposição, como são os de venda de immoveis, cessão de dividas, arrendamento a longo prazo, depende de licença judicial, concedida mediante audiencia dos interessados.

$\mathrm{Na}$ pratica do juizo divisorio, na interpretação doutrinal e interpretação judiciaria, a determinação dos poderes do inventariante não comporta actualmente duvidas serias.

Agindo, no exercicio de administração ordinaria, por prerogativa do proprio cargo, ou praticando actos de disposição ou gestão anomala, apoiado em alvará expedido com audiencia dos interessados, num e noutro caso o inventariante representa a herança.

A questão é apenas de medir-se a extensão de seus poderes, que variam conforme as circumstancias e que depen- 
dem ou independem de auctorização do juiz da causa, segundo as hypotheses occorrentes.

Dos aspectos ou desdobramento do thema, o ultimo é o mais interessante dos tres.

Pretende-se que, não sendo a herança pessoa juridica, não pode $o$ inventariante figural-a nominalmente nos actos judiciaes; pelo que, na venda de immoveis, deve a respectiva escriptura ser passada com a presença pessoal ou por procurador dos coherdeiros interessados, sempre no nome destes e nunca no da herança, que é entidade juridicamente inexistente.

Comquanto partindo do principio certo de que a herança não é pessoa juridica, é este um modo de ver errado em todas as suas conclusões, chocante da terminologia corrente, das regras da linguagem, da pratica assidua e invariavel do fôro, da doutrina do mandato, da logica e dos exemplos que o direito offerece em varias situações analogas, dos principios que regem a capacidade juridica em geral e a capacidade de ser sujeito de uma relação juridica processual em particular.

Chocante da terminologia corrente, tanto dos juristas quanto do vulgo, porque, quando têm de referir-se aos bens que compõem a fazenda que deixa um defuncto e ás pessoas nella interessadas como herdeiros ou legatarias, empregam todos a locução a herança ou a successão hereditaria de Fulano, como envolvendo em sua synthese todo o patrimonio, encargos e direitos successorios do de cujus.

As palavras herança e successão tomam-se algumas vezes como synonymas, usando-se uma e outra em dois sentidos. No sentido objectivo para significar a universalidade dos direitos activos e passivos de um defuncto taes quaes existiam no momento de sua morte; no sentido subjectivo para ex- 
primir o direito por força do qual os bens se devolvem aos herdeiros ou successores. Outras vezes destacam-se os dous termos, chamando-se herança ao acervo dos bens e successão ao direito de recebel-os.

Na phrasealogia geral emprega-se o termo em dupla accepção - ampla e restricta; na ampla abarcando todo o patrimonio do morto, com seus direitos, responsabilidades é herdeiros; na restricta cingindo apenas a universalidade dos direitos activos e passivos.

Na representação da herança nos actos juridicos do foro judicial, do foro extrajudicial ou do trafico geral dos negocios, a idéa de pessoa ou herdeiro a quem se defere é congenita ao termo.

Neste sentido, usa-se invariavelmente para traduzil-a a palavra herança ou successão hereditaria, sem declinar os herdeiros ou enumerar os seus nomes um a um; é uma expressão generica e resumida, uma palavra que traz insita na sua abreviatura a idéa do acervo de bens e da vocação dos interessados.

Nas acções litigiosas, nos processos de jurisdicção graciosa, nos arestos dos tribunaes, nas sentenças dos magistrados, na jurisprudencia eurematica mais cuidadosa, na jurisprudencia formularia mais perfeita, em juizo e fóra de juizo, todos os actos são expedidos, todos os julgados proferidos e todas as referencias feitas em nome da herança ou successão do de cujus, como termo designativo do seu patrimonio e de sua transmissão áquelles a quem legalmente toca adil-o.

Não seria possivel nem explicavel esta harmonia, constancia e diuturnidade de linguagem, si porventura a terminologia quebrantasse as regras do fallar, a realidade das cousas ou as observancias de rigor no mundo juridico.

Não só não quebranta, senão que está em concordancia com ellas. Nas leis da grammatica e da elocução, no phrasear dos eruditos e do povo, é de grande uso e não menor prestimo o emprego da synedoche, pela qual podemos significar e comprehender as partes por um termo designativo do 
todo ou um termo generico abarcando muitas individualidades.

O modo commum de fallar não se afasta do systema de direito nem dos preceitos que se guardam nemine contradicente em conjuncturas analogas.

O inventariante é equiparado a um mandatario geral. Nos actos de administração ordinaria age por si, com as prerogativas e attribuições da propria investidura; nos actos de disposição age auctorizado por alvará de licença, expedido sob a formalidade de consulta preliminar dos interessados. Advirta-se que a formalidade na hypothese de disposição é da audiencia e não da annuencia necessaria dos interessados, porque a discordancia não obsta á expedição, quando mal fundada ou contraria aos interesses da maioria ou do espolio.

Num e outro caso, age representando a herança ou patrimonio como projecção da personalidade juridica do seu auctor e daquelles que lhe succedem, no desempenho de um como mandato posthumo do defuncto e de um mandato geral deferido por lei.

Exercitando o mandato, falla em nome da herança, que é o nome que exprime o conjuncto dos bens na sua relação com os herdeiros.

A mesma coisa acontece com a herança jacente e com a massa fallida.

A herança jacente não é pessoa juridica e, no emtanto, o seu curador tem a guarda, conservação e administração de seus bens, é o representante della e, como representante, falla no nome da herança jacente e não no de seus eventuaes herdeiros. Falla como orgam directo da propria vontade, sem ser todavia o titular dos direitos que procura fazer valer; a par e passo que no seu officio tem capacidade juridica, os direitos que tutela remanescem inherentes a um patrimonio de herdeiros que não se sabe si existem. 
Em que pese á opinião em contrario de Lyon Caen et Renault, Bonelli, Lacerda de Almeida e outros grandes interpretes, a massa fallida não é pessoa juridica. Entretanto, na fallencia a sua representação activa e passiva em juizo faz-se em nome da massa. E' em nome da massa fallida e não dos credores que os syndicos e liquidatarios effectuam vendas e contractam em geral. Ninguem se refere aos bens e credores de um fallido senão pela designação de massa fallida de Fulano. Nunca se viu em actos de representação dos syndicos e liquidatarios exigir-se comparecimento dos credores.

A fallencia é um desses processos singularissimos, em que o sujeito capaz de agir não é o sujeito do direito pelo qual age. "Mentre é vero e corretto dire che il curatore (syndico ou liquidatario) no rappresenta il fallito e nemmeno i creditori ma il patrimonio in istato di fallimento. (Mortara: Procedura Civile, vol. II, n. 509 bis. Carvalho de Mendonça: Tratado de Direito Commercial, vol. VII, n. 359).

$\mathrm{Na}$ opinião dos propugnadores que sustentam o erro que profligamos, não sendo a massa fallida pessoa juridica, tambem não se poderia dizer que os syndicos e liquidatarios são representantes della nem tampouco permittirlhes que fizessem venda de immoveis sem a presença do fallido e dos credores.

A logica tem exigencias irreductiveis.

Mas a representação da herança, sob o nome de herança e não dos herdeiros, assim nos actos de administração como nos de disposição, está em plena harmonia com a construcção scientifica dos juristas, principalmente na esphera do direito judiciario.

Os processualistas illuminam a materia, de tal arte a demonstrar ainda uma vez que aquillo que se acha consagrado no uso inveterado da linguagem, da jurisprudencia e da pratica do foro judicial e extrajudicial, corresponde 
quasi sempre a uma verdade ou regra consagrada na doutrina.

Ao lado das figuras typicas e genuinas de pessoas juridicas, têm a lei e pratica plasmado outras entidades ou figuras especiaes, que, revestindo alguns elementos exteriores de pessoa, são para certos effeitos tratadas como pessoas, embora careçam do attributo essencial da pessoa, que é ser sujeito de direitos.

$\mathrm{Na}$ Allemanha, o novo regulamento processual, assim como o codigo do commercio, admittem expressamente que uma collectividade ou união, que não tem propriamente capacidade juridica, possa assumir no processo a posição de uma entidade juridicamente capaz.

Em torno deste preceito tem a escola e a jurisprudencia construido alli varias doutrinas, semelhantemente ao que succede entre os intellectuaes italianos.

Pensam alguns que taes uniões são verdadeiras pessoas juridicas, como sujeitos activos e passivos dos direitos relativos ao seu patrimonio; donde se deduz que ellas e não os individuos que a compõem é que são partes e se representam nos actos juridicos.

Entendem outros que ellas têm uma capacidade meramente formal. Os componentes individuaes é que são partes, figurando nos actos ou em juizo sob o nome collectivo.

Sustentam uns terceiros a doutrina dos chamados patrimonios autonomos - e este parece o ponto de vista real, verdadeira synthese do que se passa no mundo phenomenal juridico.

O patrimonio autonomo é a massa patrimonial pertencente a um determinado sujeito e que, porisso, não é em si mesma uma pessoa juridica. Embora, porém, tendo um sujeito determinado, é subtrahida á administração desse sujeito e confiada a um administrador que a gere em nome dessa massa; o que permitte que o patrimonio autonono se comporte no commercio juridico como um todo inde- 
pendente, analogamente a uma pessoa. Os casos principaes desta figura são a massa fallida, a herança jacente, a herança sob administração do cabeça de casal ou inventariante (Chiovenda: Istituzioni di Diritto Processuale Civile, vol. II, n. 227. Mortara: Ib., n. 505 e seg.).

Nem é outro o ponto de vista e systema entre nós.

O inventariante não é um procurador ou representante dos herdeiros; é o representante da herança, de um patrimonio autonomo e independente, que age e falla em nome da herança e não dos herdeiros.

Si em alguns casos não pode agir sem audiencia dos herdeiros, a intervenção destes se explica pelo interesse que têm na herança e não por uma representação que della não têm.

Em theoria está o thema bem fixado; praticamente não comporta duvida possivel. 